\title{
MSc course program on biomedical optics
}

Janis Spigulis

Janis Spigulis, "MSc course program on biomedical optics," Proc. SPIE 3190, Fifth International Topical Meeting on Education and Training in Optics, (8 December 1997); doi: 10.1117/12.294405

Event: Fifth International Topical Meeting on Education and Training in Optics, 1997, Delft, Netherlands 


\title{
MSc course programme on Biomedical Optics
}

\author{
Janis Spigulis \\ University of Latvia, Faculty of Physics and Mathematics, IAPS \\ Raina Blvd. 19, Riga, LV-1586, Latvia \\ E-mail: janispi@acad.latnet.lv
}

\begin{abstract}
A new Msc study course programme on Biomedical Optics has been developed and adapted. The programme consists of three main parts:

- Fundamentals of tissue optics,

- Optical sensing for diagnostics and monitoring,

- Laser-tissue interaction and laser treatment.

The full programme and some comments on it are presented.
\end{abstract}

Keywords: biomedical optics education.

\section{INTRODUCTION}

Biomedical Optics has become a significant research and clinical application area attracting wide public attention during the recent decade. Large and well-attended annual symposia and conferences on Biomedical Optics are organized in Europe (EUROPTO BIOS-Europe series), USA (SPIE BIOS-series in San Jose, CA), and elsewhere. Results of research and development are regularly published at "Journal of Biomedical Optics", "Biophotonics International" and other specialized journals. Many physicists are involved in this promising interdisciplinary area now, as well as doctors and other specialists with bio-medical background. The additionally needed knowledge and skills most of them had acquired by self-education and self-training. Only few topics of Biomedical Optics are included in traditionally well-established study programmes like Medical Physics or Bioengineering. In fact, regular study courses on Biomedical Optics at BSc and MSc levels are hardly available both in Europe and USA - mainly due to lack of textbooks, teaching methodology and internationally recognized study programmes.

The Physics Department at Faculty of Physics and Mathematics, University of Latvia, has announced a new two-year "pilot" MSc curriculum on Biomedical Optics in 1995. The basic courses included are Biomedical Optics, Lasers and Other Light Sources, Optical Medical Instruments, Medical Lightguides, Anatomy and Physiology, Optical Methods of Patient Treatment, etc.

The newly developed MSc course progamme on Biomedical Optics (128 lecture hours) is presented below. Any comments and suggestions on it would be highly appreciated.

\section{THE PROGRAMME}

\section{A. Fundamentals of tissue optics.}

1. Propagation of optical radiation in tissues.

1.1. Optical wavelength range: ultraviolet, visible and infrared spectral regions and their limits; specific " $A$ ", " $B$ " and " $C$ " bands of UV and IR. Main processes of the light-matter interaction: absorption, scattering, reflection, refraction, luminescence, interference, polarization; their physical models and mechanisms. Energetic structure of matter in gaseous, liquid and solid state, character of corresponding absorption and emission spectra.

1.2. Specific features of living tissues from the point of optics. Relations of scattering and absorption in tissues; the "therapeutic window".

1.3. Models of light propagation in tissues and the parameters used: absorption and scattering coefficients, anisotropy, penetration depth, transport parameters; their connection with diffuse reflectance (remission). Timeresolved remittance models. Modeling of anisotropic, isotropic and layered tissue structures. 
1.4. Experimental studies of light propagation in tissues; tissue phantoms in experiments. Basic principles of optical tomography.

\section{Skin optics.}

2.1. Structure of human skin. Thicknesses and optical properties of appropriate skin layers. The Kubelka Munk model. Experimental data on skin absorbance and remittance in different spectral regions. Skin pigments (melanin, bilirubin, carotene, haemoglobin) and their spectra.

2.2. Influence of UV radiation to human skin. Human erytherma action spectra. Melanogenesis (tanning) and its mechanism. Classification of human skin types according to sunburn. Sunscreens; sun protection factor (SPF) values and subsequent effects.

2.3. Principles of phototherapy. Heliotherapy. Solariums and their equipment; spectral and power parameters of solaruim lamps. Phototherapy of Hyperbilirubinemia and Psoriasis.

3. Blood optics.

2.1 Composition of blood. Spectral properties of erythrocytes, thrombocytes and blood plasma.

2.2. Differences between oxygenated and unoxygenated haemoglobin absorption spectra. Principles of optical pulse oximetry.

2.3. Routine "in vitro" blood spectral analysis in laboratories: basic requirements and equipment.

4. Optics of the hard tissues.

4.1. Structure of human bones, nails and teeth; their spectral characteristics.

4.2. Teeth fluorescence and its use for diagnosis of caries. Photopolymeric teeth fillings and their irradiation devices.

5. Eye optics.

5.1. Structure of human eye. Absorbance and refractivity of various components in ocular media. Color vision mechanism, color receptors and their spectral sensitivity.

5.2. Effects of UV-A,B,C, visible and IR-A,B,C irradiation on human vision. Retinal maximum permissible exposures of optical radiation. Eye protective filters and goggles.

\section{B. Optical sensing for diagnostics and monitoring.}

1. Biomedical optical sensors: general classification. Pure optical, physical and chemical sensors; sensors for diagnostics, patient monitoring and signalling. Invasive and non-invasive optical sensors. Optical fibre medical sensors.

2. Photoplethysmography; its use for heartbeat rate, blood supply and arterial blood pressure sensing.

3. Optical pulse oximeters: design principles. Invasive and non-invasive blood oxygen saturation measurements. Features of finger, earlobe and eye pulse oximetry. Remission-based one-touch pulse oximeters. Commercial devices.

4. Laser Doppler flowmetry: basic principles of operation. Blood supply and blood flow measurements by means of LDF. Design of invasive and non-invasive LDFs. Non-contact blood flow determination, blood flow imaging and mapping. Commercial devices.

5. Near-infrared cerebral oxygenation monitoring. Absorption of haemoglobin and cytochrome aa 3 in 700 $1000 \mathrm{~nm}$ wavelength region. Peculiarities of infant NIRO-monitoring. Commercial devices.

6. Spectrometry of human tissues. Absorption and remission in-vivo measurements of glucose, bilirubin and fat in a human body. In-vitro spectrometry in clinical laboratories and pharmacology praxis. Commercial devices.

7. Optical sensing of physical parameters. Design principles of biomedical optical sensors of temperature, pressure and displacement. Commercial devices.

8. Optical sensing of biochemical analytes. Evanescent wave devices. Fibre optic invasive biosensors for determination of $\mathrm{pH}, \mathrm{O} 2, \mathrm{CO} 2$ and other analytes in human body. Commercial devices.

9. Optical fluorescence diagnostics: main principles and applications in oncology, cardiology and dentistry.

\section{Laser-tissue interactions and laser treatment.}

1. Basic designs of medical lasers and radiation delivery devices. 
2. General mechanisms of laser-tissue interaction. Laser-caused photochemical, photothermal and photodecomposition effects; corresponding radiant doses and temperature intervals. Penetration depth of laser radiation in tissues. Cellural necrosis as a time-temperature function. Critical laser power/energy densities causing photocoagulation, carbonization, vaporization and photoablation of tissues.

3. Medical laser safety. Laser safety classes 1, 2, 3A, 3B and 4 and the corresponding potential hazards. Occupational exposure limits for commonly used lasers. Laser-protective goggles. Laser danger warning labels and their colouring. Laser safety national and international standards.

4. Low-power laser therapy and biostimulation: techniques and possible mechanisms. Laser acupuncture and wound healing.

5. Medium-power laser applications. Laser photodynamic therapy: basic idea and the optical energy transfer scheme. Designs of optical diffusers used for PDT. Port wine strain and tattoo removal by laser irradiation: physical principles.

6. High-power laser applications. Principles of laser surgery, laser angioplasty and laser dentistry. Tissue welding by laser radiation. Laser spark, bubble creation and shock wave dynamics. Advantages and applications of Holmium and Erbium lasers in medicine.

\section{INFORMATION SOURCES AND THE TWO-YEAR TEACHING EXPERIENCE}

A broad spectrum of information sources was used to prepare this programme. The books referred below (in chronological order) are very informative and useful, as well as a number of review papers from journals and proceedings which are not reflected here. One must note that Biomedical Optics is a very dynamic and rapidly developing field, therefore all recent proceedings of the SPIE and EUROPTO BIOS-conferences can be recommended to be always on the "cutting edge".

A lot of information for this programme was collected during author's 6 month stay at King's College London in 1995, especially by attending the Oxford Summer School Optics in Medicine ${ }^{11}$; also the 6 week TEMPUS-PHARE project to develop this programme at London and Linkoping universities in 1996 was very useful. A number of books and papers on specific items were found in libraries and by search in the MEDLINE database, some information on the topic is available at Internet, as well.

Two MSc student groups (8 and 9 persons) were educated following this programme in academic years $1995 / 1996$ and 1996/1997. The students were with various backgrounds - physics, engineering, biology and medicine. Generally all of them have acquired the main items of the course without significant difficulties, only few students with medical background had some problems with physical description of the biooptical phenomena in tissues. The 2 nd year students worked out their MSc thesis this spring; for illustration, there are some titles of the MSc thesis:

- Application of Tissue Fluorescence for Cancer Diagnostics,

- Phototherapy of Infant Hyperbilirubinemia,

- Image Analysis in Medical Diagnostics,

- Dosimetry Problems of Intravascular Laser Irradiation,

- Methods of Underskin Optical Monitoring.

\section{ACKNOWLEDGMENTS}

This programme could be created only thanks to support and advises of numerous Biomedical Optics professionals. The author is most obliged to Prof. D. T. Delpy, University College London, U. K., and Prof. P. A. Oberg, Linkoping University, Sweden. The financial support received in frame of the TEMPUS-PHARE grant IMG-95-LV-2007 is highly appreciated.

\section{REFERENCES}

1. J. D. Regan and J. A. Parrish, The Science of Photomedicine, Plenum Press, N-Y and London, 1982

2. D. Sliney, Safety with Lasers and Other Optical Sources, Plenum Press, NY and London, 1982

3. P. Rolfe, Non-invasive Physiological Measurements, v. 2, Academic Press, London, 1983.

4. J. P. Payne and J. W. Severinghaus, Pulse Oximetry, Springer-Verlag, Berlin, 1986.

5. J. A. S. Carruth and A. L. McKenzie, Medical Lasers: Science and Clinical Practice, Adam Hilger Ltd., Bristol and Boston, 1986. 
6. A. P. Sheperd and P. A. Oberg, Laser Doppler Blood Flowmetry, Kluwer Publ., Boston, 1990.

7. U. Dingali et al., Optical Imaging of Brain Functions and Metabolism, Plenum Press, N-Y, 1993.

8. A. Katzir, Lasers and Optical Fibers in Medicine, Academic Press, N-Y, 1993.

9. P. Vaupel et al., Oxygen Transport to Tissue XV, Plenum Press, N-Y and London, 1994.

10. BIOS Europe '94 - International Symposium on Biomedical Optics, EUROPTO, Lille, 1994.

11. Materials of the 2nd Mayneord-Phillips Summer School Optics in Medicine, Oxford, 1995.

12. A. J. Welch, M. Van Germet, Optical Thermal Response of Laser-Irradiated Tissue, Plenum Press, N-Y, 1995.

13. J. Spigulis, The Potential for Fibre Optic Sensors in Medical Monitoring, King's College London, 1995.

14. S. L. Jacques, Tissue Optics, SPIE Short Course Notes SC 34, Bellingham, 1996.

15. T. Hasan, Fundamentals of Photochemistry and Photodynamic Therapy, SPIE Short Course Notes SC 35, 1996.

16. BIOS '96 - International Symposium on Biomedical Optics: Technical Abstract Digest, SPIE, San Jose, 1996.

17. BIOS '97 - International Symposium on Biomedical Optics: Technical Abstract Digest, SPIE, San Jose, 1997. 